\title{
A Fractal Forecasting Model for Financial Time Series
}

\author{
GORDON R. RICHARDS* \\ Sprint, Kansas, USA
}

\begin{abstract}
Financial market time series exhibit high degrees of non-linear variability, and frequently have fractal properties. When the fractal dimension of a time series is non-integer, this is associated with two features: (1) inhomogeneityextreme fluctuations at irregular intervals, and (2) scaling symmetriesproportionality relationships between fluctuations over different separation distances. In multivariate systems such as financial markets, fractality is stochastic rather than deterministic, and generally originates as a result of multiplicative interactions. Volatility diffusion models with multiple stochastic factors can generate fractal structures. In some cases, such as exchange rates, the underlying structural equation also gives rise to fractality. Fractal principles can be used to develop forecasting algorithms. The forecasting method that yields the best results here is the state transition-fitted residual scale ratio (ST-FRSR) model. A state transition model is used to predict the conditional probability of extreme events. Ratios of rates of change at proximate separation distances are used to parameterize the scaling symmetries. Forecasting experiments are run using intraday exchange rate futures contracts measured at 15-minute intervals. The overall forecast error is reduced on average by up to $7 \%$ and in one instance by nearly a quarter. However, the forecast error during the outlying events is reduced by $39 \%$ to $57 \%$. The ST-FRSR reduces the predictive error primarily by capturing extreme fluctuations more accurately. Copyright (C) 2004 John Wiley \& Sons, Ltd.
\end{abstract}

KEY WORDS fractals; non-linear variability; state transitions; volatility diffusions; financial markets; exchange rates; forecasting

\section{INTRODUCTION}

Financial time series exhibit high degrees of non-linear variability, particularly at high frequencies, and often show fractal properties (Mantegna and Stanley, 1995, 1996, 1997, 1998, 1999; Schmitt et al., 1999; Calvet and Fisher, 2002). When the fractal dimension of a time series is non-integer, or equivalently when the codimension is non-zero, this is associated with two characteristic features. First, fractal processes exhibit inhomogeneity - a high probability of extreme or outlying fluctuations, generally at irregular intervals. Second, fractal processes also exhibit scaling symmetries-

* Correspondence to: Gordon R. Richards, Sprint Telecommunications, 6180 Sprint Parkway, Overland Park, KS 66251, USA. E-mail: Econ1955@msn.com

Copyright (C) 2004 John Wiley \& Sons, Ltd. 
proportionality relationships between fluctuations at different separation distances. Evidence of fractality in financial markets does not imply chaoticity_-behaviour reminiscent of randomness produced by a small number of deterministic equations. Prior studies have found no evidence of chaotic attractors (Brock and Sayers, 1988; Hsieh, 1991, 1993). Instead, fractality in large-scale multivariate systems such as financial markets is stochastic and high-dimensional. This type of fractality generally originates as a result of multiplicative interactions between two or more stochastic processes.

Much of the recent literature on non-linear variability in financial markets has been based on volatility diffusions with multiple stochastic factors. References include Andersen (1994), Andersen and Lund (1997), Andersen and Bollerslev (1997), Andersen et al. (1999), Bollerslev and Mikkelsen (1996), Bates (1996), Fouque et al. (2000), Gallant et al. (1999). Volatility diffusions with multiplicative relationships between stochastic factors will as a rule generate fractality. Let $W_{i t}$ denote $i$ separate Levy motions, let $U_{j t}$ denote $j$ separate stochastic factors, let $\sigma$ be the diffusion coefficient or positive root of the variance, and let $Y_{t}$ be a time series. The following equations describe a multiple factor diffusion in continuous time:

$$
\begin{aligned}
& d Y_{t}=\left(\omega_{10}+\omega_{12} U_{2 t}\right) d t+\sigma\left(\omega_{10}^{\prime}+\omega_{13}^{\prime} U_{3 t}\right)\left(\bar{\omega}_{11} d W_{1 t}+\bar{\omega}_{13} d W_{3 t}\right) \\
& d U_{21}=\left(\omega_{20}+\omega_{22} U_{2 t}\right) d t+\omega_{20} d W_{2 t} \\
& d U_{3 t}=\left(\omega_{30}+\omega_{31} U_{3 t}\right) d t+\left(\omega_{30}^{\prime}+\omega_{31}^{\prime} U_{3 t}\right) d W_{3 t}
\end{aligned}
$$

where the $\omega, \dot{\omega}, \bar{\omega}$ are fixed coefficients. The stochastic factors $U_{2 t}$ and $U_{3 t}$ evolve according to Ornstein-Uhlenbeck processes. The second factor $U_{2 t}$ allows for variation in the drift. The diffusion coefficient varies as a function of the stochastic factor $U_{3 t}$ and the Levy motions $d W_{1 t}, d W_{3 t}$. Because of the multiplicative relationship between the Levy motion terms in equations (1) and (3), simulations of this type of model invariably give rise to fractal structures, as reported below.

At longer separation distances, financial series can be modelled using structural equations, which are generally non-fractal. In this sense, it is reasonable to characterize economic time series as exhibiting fractal properties at short horizons, but converging to equilibria asymptotically. In some instances, however, the underlying structural equations will also generate fractality. The clearest case in point is the exchange rate, hypothesized to be determined by differentials in real rates of return. Let $X_{t}$ be the exchange rate, let $I_{t}$ be the interest rate, let the superscript $e$ denote expectations, let $\varepsilon_{t}$ be the residual, and let the subscript $F$ denote foreign. The structural equation is of the form:

$$
\ln X_{t}=\omega_{0}+\omega_{1} \ln X_{t-1}+\omega_{2}\left[\left(\ln I_{t}-\ln \pi_{1}^{e}\right)-\left(\ln I_{F l}-\ln \pi_{F t}^{e}\right)\right]+\varepsilon_{l}
$$

As pointed out in Mandelbrot (1997), taking ratios of stochastic processes can give rise to non-linear variability. For this reason, the term $\left[\left(\ln I_{t}-\ln \pi_{t}^{e}\right)-\left(\ln I_{F t}-\ln \pi_{F t}^{e}\right)\right]$ implies fractal behaviour. Moreover, nominal and real interest rates can also be shown to be fractal, so that the differential in real rates of return is itself a difference of two independently fractal processes.

If fractality is found in economic series, the issue arises as to whether it can be exploited in order to forecast. The forecasting algorithms analysed here combine two methods. One is to predict the conditional probability of extreme events using a state transition model. The other is to build a model of the scaling symmetries at short horizons. The second section discusses some analytic concepts. The third section sets out the forecasting models. The fourth section estimates the fractal codimension, order of integration and probability distribution for exchange rates, exchange rate futures con- 
tracts and interest rates. The fifth section conducts forecasting experiments. The sixth section discusses the relationship between fractals, ARCH models and volatility diffusions.

\section{THE FRACTAL DIMENSION AND THE SCALING SYMMETRY}

There are any number of definitions of dimensionality in the fractal literature; probabilistic measures such as the information and pointwise dimensions are more relevant to stochastic processes (Medio, 1992). The basic idea is that the number of occurrences of a process falling outside a particular threshold or boundary behaves as a power law. Let $N$ be the number of events, let $L$ be the characteristic length, and let $D$ be the embedding dimension of the space that encompasses the process; for a time series, $D=1$. Let $d$ be the fractal dimension. A probabilistic measure of dimensionality for the absolute $\log$-difference of $Y_{t}$ is given by: $\ln \left[N\left(\left|\ln Y_{t}-\ln Y_{t-1}\right|\right)>L / N\left(\mid \ln Y_{t}-\right.\right.$ $\left.\left.\ln Y_{t-1} \mid\right)\right] / \ln L$. The share of observations that lie outside the threshold, $L$, relative to the total sample, varies as a power-law function of the dimension:

$$
\left[N\left(\left|\ln Y_{t}-\ln Y_{t-1}\right|\right)>L / N\left(\left|\ln Y_{t}-\ln Y_{t-1}\right|\right)\right] \approx L^{d}
$$

where $\approx$ denotes asymptotic equality. In this sense, dimensionality is a measure of entropy or disorder.

The dimension varies as a function of the threshold, and therefore has often been measured as the asymptotic limit as the threshold approaches zero. A more recent idea is to estimate the average inhomogeneity of the process, using the codimension, $C$, which is the difference between the embedding dimension and the fractal dimension: $C=D-d$. For all $C \neq 0$, the process is said to be fractal. At low degrees of fractality ( $C$ close to zero), the process is more homogenous: there are few extreme fluctuations. Conversely, for higher values of $C$, there are more extreme events, or fluctuations outside the threshold. The process becomes less homogenous, more intermittent, sparser and more volatile.

The codimension formalism and the overall mathematical framework used here is that of Schertzer and Lovejoy (1991); see also Schertzer et al. (1997); Schmitt et al. (1992, 1993); Lavallee et al. (1991, 1992). The relationship between the codimension and the scaling symmetry is given by the following equations. Let $\tau$ be a time scale running from 1 to $T$, where $T$ is the largest horizon of interest. Let $\mu$ denote the mean. Let $q$ denote a series of scaling exponents. The scaling symmetry is of the form:

$$
\mu\left(\left|\ln Y_{t}-\ln Y_{t-1}\right|^{q}\right) \approx\left[\mu\left(\left|\ln Y_{t}-\ln Y_{t-T}\right|^{q}\right)\right]\left[(\tau / T)^{\zeta(q)}\right]
$$

where $\zeta$ is a function. This states that the mean absolute log-difference (raised to the power $q$ ) is proportional to the mean absolute log-difference at larger separations in time, when scaled by the term $\left[(\tau / T)^{\zeta(q)}\right]$. The theoretical form of $\zeta(q)$ is universal and incorporates three parameters, denoted $C_{1}, H, \alpha$ :

$$
\begin{aligned}
& \zeta(q)=q H-\left\{\left[C_{1} /(\alpha-1)\right]\left(q^{\alpha}-q\right)\right\} \quad \text { when } \alpha \neq 1 \\
& \zeta(q)=q H-\left(C_{1} q \ln q\right) \quad \text { when } \alpha=1
\end{aligned}
$$


The parameter $C_{1}$ is the codimension associated with scaling the sample means. When $C_{1}=0$, $\zeta(q)$ is a linear trend. When $C_{1} \neq 0$, the curvature of $\zeta(q)$ depends on both the codimension and the probability distribution. The coefficient $\alpha$ characterizes the probability distribution. The case of $\alpha=$ 2 corresponds to the Gaussian, while $\alpha=1$ corresponds to the Cauchy. Most economic processes show $1<\alpha<2$. In this case the distribution has heavier tails than the standard normal, and the variance is time-varying. An interesting property of series that exhibit both $1<\alpha<2$ and $0<C_{1}<1$ is that integration generally does not result in a smooth path for the level series. Instead, the integral will exhibit discrete jumps.

The coefficient $H$ characterizes the non-conservation of the mean. The notation $H$ actually originates with the Hurst exponent, or rescaled range coefficient, a widely used measure of memory (Hurst, 1951). In this framework, however, $H$ is estimated as one in a series of scaling coefficients. This statistic is related to the order of integration by an additive constant. For an $\mathrm{I}(0)$ process, $H=$ 0.5 . For a non-stationary process, the order of integration can be recovered by estimating $H$ on the rate of change (Beran, 1992). This method is robust both to non-linearity and to fractional orders of integration.

\section{THE FORECASTING ALGORITHMS}

Given the dual properties of extreme events and scaling symmetries, it is natural to develop models that can capture both features. State transition models have been common in the literature (Gray, 1996; Hamilton, 1989, 1994; Terasvirta, 1994). The state transition is here specified for the transition from a state of low or intermediate variability to an extreme state, and is denoted $S_{E t}$. The state transition model for the exchange rate can be specified as:

$$
\begin{aligned}
\ln X_{t+1}= & \omega_{0}+\omega_{1} \ln X_{t}+\omega_{2}\left[\left(\ln I_{t}-\ln \pi_{t}^{e}\right)-\left(\ln I_{F t}-\ln \pi_{F t}^{e}\right)\right]+\omega_{3} S_{E t} \ln X_{t} \\
& +\omega_{4} S_{E t}\left[\left(\ln I_{t}-\ln \pi_{t}^{e}\right)-\left(\ln I_{F t}-\ln \pi_{F t}^{e}\right)\right]+\varepsilon_{t}
\end{aligned}
$$

The state can be predicted iteratively using a regression of the form:

$$
S_{E t+1}=\omega_{0}+\omega_{1} S_{E t}+\omega_{2} \ln X_{t}+\omega_{3}\left(\ln X_{t}-\ln X_{l-1}\right)+\varepsilon_{l}
$$

where the rate of change as well as the level of the exchange rate is included on the RHS on the grounds that in practical applications this was found to improve the results.

This type of model does of course have one intrinsic risk: the state transitions may be predicted incorrectly. To guard against this possibility, models with and without state transitions should be estimated. A further issue in implementation is that including state transitions on all of the RHS variables can make the model too complex. A limited number of state transitions, on selected causal factors, may be preferable. A final problem is how to specify the extreme event. This can be determined empirically, by testing the values that yield the best forecasts. In the tests below, absolute rates of change two to five times greater than the conditional mean were essayed, and were found to yield good results.

The idea of using the scaling symmetry in order to forecast was originally proposed in Schertzer et al. (1997, pp. 456-458) for physical processes that exhibit strong symmetries between large and small scales. Since proportionality relationships in economic series are generally limited to shorter intervals, the models here use only the proximate symmetry. The following equations were set out 
in Richards (2002). For the predicted rate of change, there is a symmetry with respect to the most recent lag:

$$
\left(\ln X_{t+1}-\ln X_{t}\right)=\lambda_{1 t}\left(\ln X_{t+1}-\ln X_{t-1}\right)
$$

where $\lambda_{1 t}$ is the proportionality coefficient, the numerical subscript denotes the separation distance on the RHS, and the $t$-subscript indicates time-variation. Similarly, for the observed rates of change:

$$
\left(\ln X_{t}-\ln X_{t-1}\right)=\lambda_{2 t}\left(\ln X_{t}-\ln X_{t-2}\right)
$$

Solving for $\lambda_{2 t}$ :

$$
\lambda_{2 t}=\left[\left(\ln X_{t}-\ln X_{t-1}\right) /\left(\ln X_{t}-\ln X_{t-2}\right)\right]
$$

One practical problem in implementation is that the denominators of the ratios may contain zero values. Any number of interpolation procedures can be used to impute missing values. In the experiments below, when the ratio was indeterminate, the data was exponentially smoothed, and the ratio based on the smoothed data was substituted. Other imputation methods yielded similar results. The forecasting model for the overall process is then:

$$
\ln X_{t+1}=\omega_{0}+\omega_{1} \ln X_{t}+\omega_{2}\left[\left(\ln I_{t}-\ln \pi_{t}^{e}\right)-\left(\ln I_{F t}-\ln \pi_{F l}^{e}\right)\right]+\omega_{3} \lambda_{2 t}+\varepsilon_{l}
$$

As noted above, most structural equations in macroeconomics do not imply long-term fractality. This argues for fitting a structural equation, and constructing the scale ratios for the residual:

$$
\begin{aligned}
& \left(\varepsilon_{l}-\varepsilon_{t-1}\right)=\gamma_{2 t}\left(\varepsilon_{t}-\varepsilon_{t-2}\right) \\
& \gamma_{2 t}=\left[\left(\varepsilon_{t}-\varepsilon_{t-1}\right) /\left(\varepsilon_{t}-\varepsilon_{1-2}\right)\right]
\end{aligned}
$$

where $\gamma_{2 t}$ is the proportionality coefficient for the residual. The forecasting model therefore becomes:

$$
\ln X_{t+1}=\omega_{0}+\omega_{1} \ln X_{t}+\omega_{2}\left[\left(\ln I_{t}-\ln \pi_{t}^{e}\right)-\left(\ln I_{F t}-\ln \pi_{F t}^{e}\right)\right]+\omega_{3} \gamma_{2 t}+v_{t}
$$

where $v_{t}$ is the residual from this regression. This is the residual scale ratio (RSR) model.

The main drawback associated with the SR and RSR models is that the scale ratios are known only for the current period. Further, in practical tests, the scale ratios were often found to be too volatile to forecast effectively. A reasonable solution is to factor the scale ratio into two components, a systematic process and a residual. Let $\gamma_{2 S t}$ denote the systematic component in $\gamma_{2 t}$. Generally, the forecaster does not know the form of this component, but can estimate it using a regression on lags:

$$
\gamma_{2 S t}=\omega_{0}+\omega_{1} \gamma_{2 l-1}+\omega_{2} \gamma_{2 t-2}+v_{t}
$$

The predicted value, $\gamma_{2 S t+1}$, is then included in the forecasting equation. This is the fitted residual scale ratio (FRSR) model:

$$
\ln X_{t+1}=\omega_{0}+\omega_{1} \ln X_{t}+\omega_{2}\left[\left(\ln I_{t}-\ln \pi_{t}^{e}\right)-\left(\ln I_{F t}-\ln \pi_{F t}^{e}\right)\right]+\omega_{3} \gamma_{2 S t+1}+v_{t}
$$


The same procedure can be used for the simple scale ratio, yielding the FSR model. All the scale ratio models can be augmented with state transition terms, yielding the class of state transition scale ratio models (ST-SR, ST-RSR, ST-FSR, ST-FRSR).

\section{ESTIMATION OF THE FRACTAL PARAMETERS}

Estimation of the fractal parameters is based on scaling the log means of the absolute logdifferences over increasing separation distances [see equations (6) and (7)]. In effect, this exploits the relationship between the scaling symmetry and the function $\zeta(q)$. The mean $(\mu)$ is the sample mean of the data. The series of scaling exponents, $q$, can include negative as well as positive values, but here runs from 0.1 to 4.0 , in increments of 0.1 . The initial stage is to compute the scaling:

$$
\begin{aligned}
& \ln Y_{\tau}=\ln \left[\mu\left(\left|\ln Y_{t}-\ln Y_{l-1}\right|^{q}\right)\right] \quad \text { at time } t=1 \\
& \ln \Upsilon_{\tau}=\ln \left[\mu\left(\left|\ln Y_{t}-\ln Y_{t-2}\right|^{q}\right)\right] \quad \text { at time } t=2 \\
& \ln \Upsilon_{\tau}=\ln \left[\mu\left(\left|\ln Y_{t}-\ln Y_{t-1}\right|^{q}\right)\right] \quad \text { at time } t=T
\end{aligned}
$$

where $Y_{\tau}$ is a time series running from 1 to $T$. The procedure is repeated for each value of $q$. In the second stage, each series $\ln Y_{\tau q}$ corresponding with a value of $q$ is regressed on the log of the time scale:

$$
\ln \Upsilon_{\tau q}=\omega_{0}+\omega_{1} \ln \tau_{1}+\varepsilon_{t}
$$

The coefficient $\omega_{1}$ estimates $\zeta(q)$ for each value of $q$.

From equation (7), when $q=1$, the expression $\left[C_{1} /(\alpha-1)\right]\left(q^{\alpha}-q\right)$ equals zero and $\zeta(q)=H$. Equivalently, $H=\zeta(1)$. When $1<\alpha<2$, the values of $C_{1}$ and $\alpha$ are estimated using the first derivative of $\zeta(q)$ at the origin, denoted $\zeta^{\prime}(0)$ (Schertzer et al., 1997, p. 445). This term is equal to $\zeta(1)$ plus a second term, which is a power-law function of $\alpha$ :

$$
\zeta^{\prime}(0)=\zeta(1)+\kappa^{\alpha}\left[C_{1} /(\alpha-1)\right]
$$

where $\kappa$ is a constant. Multiplying both sides by $q$ and subtracting $\zeta(q)$ from both yields:

$$
\left[q \zeta^{\prime}(0)-\zeta(q)\right]=q \kappa^{\alpha}\left[C_{1} /(\alpha-1)\right]
$$

which in turn implies the log-linear regression:

$$
\ln \left[q \zeta^{\prime}(0)-\zeta(q)\right]=\omega_{0}+\omega_{t} \ln q+\varepsilon_{t}
$$

The coefficient $\omega_{1}$ estimates $\alpha$. The antilog of the intercept is equal to $\left[C_{1} /(\alpha-1)\right]$, so that the codimension can be estimated as $C_{1}=\left[\exp \left(\omega_{0}\right)\right](\alpha-1)$.

Because fractality is in evidence mainly at high frequencies, the primary data set used here consists of five intraday foreign exchange futures contracts. These are proprietary series obtained from the Futures Communications Company, Inc., for futures contracts traded on American exchanges. 


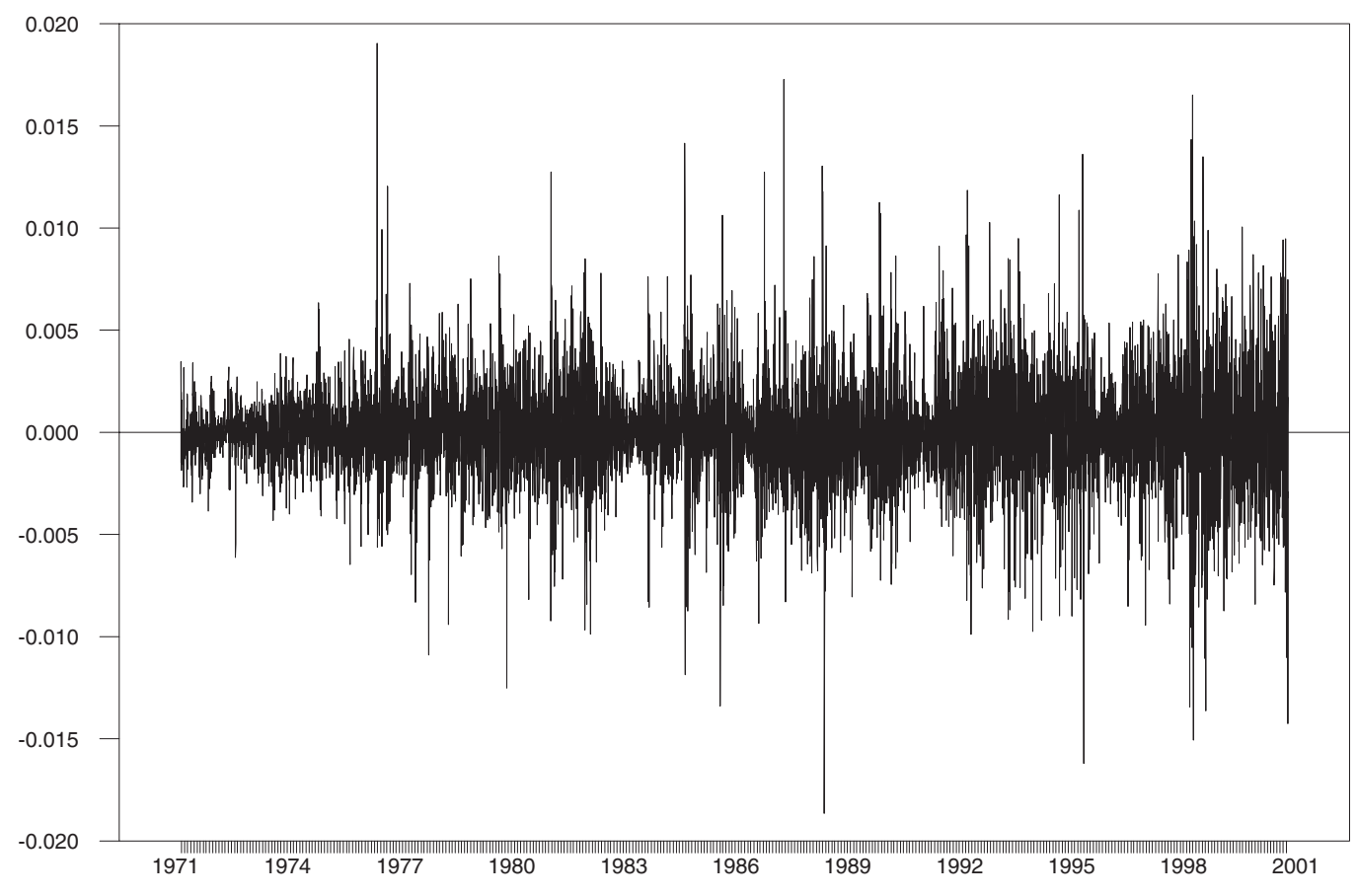

Figure 1. Log-difference, US-Canada exchange rate, 1971-2001

The measurement interval is one observation every 15 minutes. Four sets of contracts are traded, with expirations at the end of each quarter. The series tested are the September contracts for the Canadian dollar and German mark, the June contracts for the Swiss franc and the Japanese yen, and the December contract for the British pound. The Canadian dollar contract runs from 1 July, 1976 to 31 December 1998, and provides 88,899 observations. The other contracts start in December 1977, and run through the end of 1998 . The number of observations is 79,984 for Germany, 79,799 for Switzerland and 85,846 for the United Kingdom.

Daily actual exchange rate series for the same five countries are also analyzed; these series were obtained from the US Federal Reserve. The sample period is 24 August 1971, coinciding with the breakdown of the Bretton Woods fixed exchange rate system, through April 2001, except for the German mark, which runs until 31 December 1998. Figure 1 shows the log first-difference of the Canadian dollar. The fractal structure is evident in the intermittent outlying values. The other exchange rates show similar patterns.

Table I presents the estimated parameters, using an outer horizon of 200 days. This rather short value for the outer horizon was determined empirically. At long horizons, the codimension falls to zero, consistent with the idea that economic time series possess long-term equilibria. For the exchange rate, the differential in real rates of return will be gradually equalized by arbitrage. At extremely short horizons, however, the scaling function is often inestimable. From equation (22), when $\left[q \zeta^{\prime}(0)-\zeta(q)\right]<0$, equation $(23)$ is indeterminate. In essence, the scaling function yields meaningful values only for a particular range of time horizons. 
Table I. Estimated parameters

\begin{tabular}{|c|c|c|c|c|}
\hline Time series & $H$ & $I(n)$ & $\alpha$ & $C_{1}$ \\
\hline $\begin{array}{l}\text { Canadian dollar } \\
\text { Futures contract } \\
\text { Exchange rate } \\
\text { Fitted residual scale ratio }\end{array}$ & $\begin{array}{l}0.52 \\
0.54 \\
\ldots\end{array}$ & $\begin{array}{l}1.02( \pm 0.002) \\
1.04( \pm 0.002) \\
0.02( \pm 0.002)\end{array}$ & $\begin{array}{l}1.61( \pm 0.02) \\
1.88( \pm 0.01) \\
1.21( \pm 0.01)\end{array}$ & $\begin{array}{l}0.042( \pm 0.04) \\
0.051( \pm 0.02) \\
0.041( \pm 0.03)\end{array}$ \\
\hline $\begin{array}{l}\text { German mark } \\
\text { Futures contract } \\
\text { Exchange rate } \\
\text { Fitted residual scale ratio }\end{array}$ & $\begin{array}{l}0.58 \\
0.58 \\
\ldots\end{array}$ & $\begin{array}{l}1.08( \pm 0.002) \\
1.08( \pm 0.002) \\
0.06( \pm 0.002)\end{array}$ & $\begin{array}{l}1.89( \pm 0.015) \\
1.87( \pm 0.03) \\
1.18( \pm 0.015)\end{array}$ & $\begin{array}{l}0.048( \pm 0.03) \\
0.041( \pm 0.07) \\
0.021( \pm 0.03)\end{array}$ \\
\hline $\begin{array}{l}\text { Japanese yen } \\
\text { Futures contract } \\
\text { Exchange rate } \\
\text { Fitted residual scale ratio }\end{array}$ & $\begin{array}{l}0.57 \\
0.57 \\
\ldots\end{array}$ & $\begin{array}{l}1.07( \pm 0.002) \\
1.07( \pm 0.002) \\
0.08( \pm 0.002)\end{array}$ & $\begin{array}{l}1.95( \pm 0.01) \\
1.86( \pm 0.02) \\
1.37( \pm 0.02)\end{array}$ & $\begin{array}{l}0.085( \pm 0.02) \\
0.031( \pm 0.05) \\
0.050( \pm 0.04)\end{array}$ \\
\hline $\begin{array}{l}\text { Swiss franc } \\
\text { Futures contract } \\
\text { Exchange rate } \\
\text { Fitted residual scale ratio }\end{array}$ & $\begin{array}{l}0.59 \\
0.57 \\
\ldots\end{array}$ & $\begin{array}{l}1.09( \pm 0.002) \\
1.07( \pm 0.002) \\
0.06( \pm 0.002)\end{array}$ & $\begin{array}{l}1.83( \pm 0.03) \\
1.79( \pm 0.04) \\
1.26( \pm 0.01)\end{array}$ & $\begin{array}{l}0.051( \pm 0.06) \\
0.044( \pm 0.08) \\
0.038( \pm 0.02)\end{array}$ \\
\hline $\begin{array}{l}\text { UK pound } \\
\text { Futures contract } \\
\text { Exchange rate } \\
\text { Fitted residual scale ratio }\end{array}$ & $\begin{array}{l}0.59 \\
0.57 \\
\ldots\end{array}$ & $\begin{array}{l}1.09( \pm 0.002) \\
1.07( \pm 0.002) \\
0.07( \pm 0.002)\end{array}$ & $\begin{array}{l}1.78( \pm 0.02) \\
1.81( \pm 0.02) \\
1.21( \pm 0.01)\end{array}$ & $\begin{array}{l}0.038( \pm 0.04) \\
0.040( \pm 0.05) \\
0.027( \pm 0.02)\end{array}$ \\
\hline Federal funds rate & 0.52 & $1.02( \pm 0.03)$ & $1.98( \pm 0.008)$ & $0.082( \pm 0.016)$ \\
\hline 90-day Treasury bill rate & 0.53 & $1.03( \pm 0.04)$ & $1.95( \pm 0.007)$ & $0.059( \pm 0.015)$ \\
\hline
\end{tabular}

Note: $H$ is estimated as $\zeta(1)$, rather than as the rescaled range coefficient. $I(n)$ is to the order of integration. $C_{1}$ is the fractal codimension of the mean, and $\alpha$ is the coefficient characterizing the probability distribution.

The probability distribution has heavy tails: $\alpha$ ranges from 1.61 to 1.95 for the futures contract, and 1.79 to 1.88 for the actual exchange rate. The degree of fractality is low: the codimension ranges from 0.038 to 0.085 for the futures contract, and 0.031 to 0.051 for the actual exchange rate. The values of $H$ range from 0.52 to 0.59 , implying that the order of integration is fractional, but very close to unity: I(1.02) to I(1.09).

Given the relationship postulated in equation (4), it is also germane to test interest rates. The final lines show the results for two short-term interest rates in the United States, the Federal funds rate and 90-day Treasury bill rates, again at a daily frequency, estimated for 1971-2001. These series are also very close to the unit root case. The probability distribution has lighter tails: $\alpha=1.95$ to 1.98. The degree of fractality is higher for the Federal funds rate: $C_{1}=0.082$, compared to $C_{1}=0.059$ for the Treasury bill rate. This may reflect the way in which the Federal Reserve has targeted the overnight rate, engineering abrupt level shifts followed by periods of greater stability. 


\section{FORECASTING EXPERIMENTS}

This section conducts a series of forecasting experiments, testing the scale ratio models against each other and the well-known GARCH (Bollerslev, 1986) and EGARCH (Nelson, 1991) models. Both models are specified with a generalized probability distribution. The main emphasis is on the exchange rate futures contract, denoted $X_{C t}$. Because of the high frequency of the futures data, a structural equation cannot be estimated, and the basic predictive model is simply a regression on one lag of the LHS:

$$
\ln X_{C t}=\omega_{0}+\omega_{1} \ln X_{\mathrm{C} t-1}+\varepsilon_{t}
$$

The residual used in the RSR and ST-RSR models is the residual from this regression. Two daily series were also tested, the Federal funds rate and the US Canada exchange rate. Let $\bar{Y}_{t}$ denote real output. The basic forecasting equations for daily interest rates and the exchange rate are:

$$
\begin{aligned}
& \ln I_{t+1}=\omega_{0}+\omega_{1} \ln I_{t}+\omega_{2}\left(\ln \bar{Y}_{t}-\ln \bar{Y}_{t-1}\right)+\omega_{3} \ln \pi_{t}+\varepsilon_{t} \\
& \ln X_{t+1}=\omega_{0}+\omega_{1} \ln X_{t}+\omega_{2}\left[\left(\ln I_{t}-\ln \pi_{t}^{e}\right)-\left(\ln I_{F t}-\ln \pi_{F t}^{e}\right)\right]+\varepsilon_{t}
\end{aligned}
$$

The interest rates are the US Federal funds and the Canadian overnight rate. Inflation is the CPI, and real output is the index of industrial production, interpolated to a daily frequency.

Each of these models was first estimated over the first 1000 data points, and forecasted iteratively one period ahead through the entire sample using the Kalman filter (Kalman, 1960). While the Kalman filter does not directly take account of the non-linear behaviour of the time-varying variance, it does provide consistent estimators of the Gaussian quasi-likelihood. The initial run of the model then serves as the baseline against which the other, more complex models are evaluated. The forecast criterion is the root mean square error (RMSE). However, the key test of the fractal models is not so much the overall ability to forecast, but rather the ability to forecast outlying fluctuations (see on this issue Huisman et al., 2001). For this reason, the RMSE during the extreme state is also reported. To facilitate comparisons, each of the forecast errors is also expressed as a ratio to the forecast error generated by the basic model. Values below unity measure the percentage improvement in forecast accuracy.

Before running the forecasts, it is of interest to analyse the fractal properties of the scale ratio terms. Table I reports the results for the fitted residual scale ratio, for each of the five futures contracts. The estimates for $C_{1}$ are similar to the actual futures contract series. In most cases, however, the probability distribution has heavier tales.

Table II, Parts 1 through 5, gives the results of the experiments for the exchange rate futures contracts. The results strongly favour the ST-FRSR model. For the full sample, the reduction in the RMSE in this model is in the range of $1-7 \%$ in Canada, Germany, Japan and Switzerland, and a much more decisive $24 \%$ in the United Kingdom. The most dramatic improvement in the forecast error occurs during the outlying events, where the ST-FRSR reduces the RMSE by $39 \%$ to $57 \%$. In two countries, Canada and the United Kingdom, the ST-EGARCH and ST-GARCH models yield approximately the same forecast errors for the outlying fluctuations as the ST-FRSR.

Table II, Parts 6 and 7, give the results for the daily Canadian dollar and the Federal funds rate. In both cases, the ST-EGARCH, rather than one of the scale ratio models, achieves the smallest forecast error. 
Table II. Model forecasting performance

\begin{tabular}{|c|c|c|c|c|}
\hline Model & RMSE & RMSE (outliers) & Ratio & Ratio (outliers) \\
\hline \multicolumn{5}{|c|}{$\begin{array}{l}\text { Part 1: Canada } \\
\text { Exchange rate futures contract }\end{array}$} \\
\hline $\begin{array}{l}\text { Basic model } \\
\text { SR } \\
\text { RSR } \\
\text { FSR } \\
\text { FRSR } \\
\text { GARCH } \\
\text { EGARCH }\end{array}$ & $\begin{array}{l}3.14 \mathrm{E}-04 \\
3.14 \mathrm{E}-04 \\
3.14 \mathrm{E}-04 \\
3.14 \mathrm{E}-04 \\
3.14 \mathrm{E}-04 \\
3.14 \mathrm{E}-04 \\
3.14 \mathrm{E}-04\end{array}$ & $\begin{array}{l}1.86 \mathrm{E}-04 \\
1.86 \mathrm{E}-04 \\
1.86 \mathrm{E}-04 \\
1.86 \mathrm{E}-04 \\
1.86 \mathrm{E}-04 \\
1.86 \mathrm{E}-04 \\
1.86 \mathrm{E}-04\end{array}$ & $\begin{array}{l}1.00 \\
1.00 \\
1.00 \\
1.00 \\
1.00 \\
1.00\end{array}$ & $\begin{array}{l}\ldots \\
1.00 \\
1.00 \\
1.00 \\
1.00 \\
1.00 \\
1.00\end{array}$ \\
\hline $\begin{array}{l}\text { ST-Basic model } \\
\text { ST-SR } \\
\text { ST-RSR } \\
\text { ST-FSR } \\
\text { ST-FRSR } \\
\text { ST-GARCH } \\
\text { ST-EGARCH }\end{array}$ & $\begin{array}{l}3.15 \mathrm{E}-04 \\
3.15 \mathrm{E}-04 \\
3.15 \mathrm{E}-04 \\
3.15 \mathrm{E}-04 \\
3.00 \mathrm{E}-04 * \\
3.12 \mathrm{E}-04 \\
3.06 \mathrm{E}-04\end{array}$ & $\begin{array}{l}1.86 \mathrm{E}-04 \\
1.86 \mathrm{E}-04 \\
1.86 \mathrm{E}-04 \\
1.86 \mathrm{E}-04 \\
9.55 \mathrm{E}-05^{*} \\
9.66 \mathrm{E}-05 \\
9.55 \mathrm{E}-05^{*}\end{array}$ & $\begin{array}{l}1.00 \\
1.00 \\
1.00 \\
1.00 \\
0.95^{*} \\
0.99 \\
0.97\end{array}$ & $\begin{array}{l}1.00 \\
1.00 \\
1.00 \\
1.00 \\
0.51 * \\
0.52 \\
0.51 *\end{array}$ \\
\hline \multicolumn{5}{|c|}{$\begin{array}{l}\text { Part 2: Germany } \\
\text { Exchange rate futures contract }\end{array}$} \\
\hline $\begin{array}{l}\text { Basic model } \\
\text { SR } \\
\text { RSR } \\
\text { FSR } \\
\text { FRSR } \\
\text { GARCH } \\
\text { EGARCH }\end{array}$ & $\begin{array}{l}7.27 \mathrm{E}-04 \\
7.27 \mathrm{E}-04 \\
7.28 \mathrm{E}-04 \\
7.27 \mathrm{E}-04 \\
7.27 \mathrm{E}-04 \\
7.27 \mathrm{E}-04 \\
7.28 \mathrm{E}-04\end{array}$ & $\begin{array}{l}4.20 \mathrm{E}-03 \\
4.20 \mathrm{E}-03 \\
4.20 \mathrm{E}-03 \\
4.20 \mathrm{E}-03 \\
4.20 \mathrm{E}-03 \\
4.20 \mathrm{E}-03 \\
4.21 \mathrm{E}-03\end{array}$ & $\begin{array}{l}1.00 \\
1.00 \\
1.00 \\
1.00 \\
1.00 \\
1.00\end{array}$ & $\begin{array}{l}\ldots \\
1.00 \\
1.00 \\
1.00 \\
1.00 \\
1.00 \\
1.00\end{array}$ \\
\hline $\begin{array}{l}\text { ST-Basic model } \\
\text { ST-SR } \\
\text { ST-RSR } \\
\text { ST-FSR } \\
\text { ST-FRSR } \\
\text { ST-GARCH } \\
\text { ST-EGARCH }\end{array}$ & $\begin{array}{l}7.28 \mathrm{E}-04 \\
7.28 \mathrm{E}-04 \\
7.29 \mathrm{E}-04 \\
7.28 \mathrm{E}-04 \\
6.82 \mathrm{E}-04 * \\
7.12 \mathrm{E}-04 \\
7.05 \mathrm{E}-04\end{array}$ & $\begin{array}{l}4.21 \mathrm{E}-03 \\
4.21 \mathrm{E}-03 \\
4.21 \mathrm{E}-03 \\
4.21 \mathrm{E}-03 \\
2.45 \mathrm{E}-03 * \\
2.54 \mathrm{E}-03 \\
2.55 \mathrm{E}-03\end{array}$ & $\begin{array}{l}1.00 \\
1.00 \\
1.00 \\
1.00 \\
0.93 * \\
0.98 \\
0.97\end{array}$ & $\begin{array}{l}1.00 \\
1.00 \\
1.00 \\
1.00 \\
0.58 * \\
0.60 \\
0.60\end{array}$ \\
\hline \multicolumn{5}{|c|}{$\begin{array}{l}\text { Part 3: Japan } \\
\text { Exchange rate futures contract }\end{array}$} \\
\hline $\begin{array}{l}\text { Basic model } \\
\text { SR } \\
\text { RSR } \\
\text { FSR } \\
\text { FRSR } \\
\text { GARCH } \\
\text { EGARCH }\end{array}$ & $\begin{array}{l}6.39 \mathrm{E}-04 \\
6.39 \mathrm{E}-04 \\
6.39 \mathrm{E}-04 \\
6.39 \mathrm{E}-04 \\
6.39 \mathrm{E}-04 \\
6.39 \mathrm{E}-04 \\
6.40 \mathrm{E}-04\end{array}$ & $\begin{array}{l}4.51 \mathrm{E}-03 \\
4.51 \mathrm{E}-03 \\
4.51 \mathrm{E}-03 \\
4.51 \mathrm{E}-03 \\
4.51 \mathrm{E}-03 \\
4.51 \mathrm{E}-03 \\
4.53 \mathrm{E}-03\end{array}$ & $\begin{array}{l}1.00 \\
1.00 \\
1.00 \\
1.00 \\
1.00 \\
1.00\end{array}$ & $\begin{array}{l}1.00 \\
1.00 \\
1.00 \\
1.00 \\
1.00 \\
1.00\end{array}$ \\
\hline $\begin{array}{l}\text { ST-Basic model } \\
\text { ST-SR } \\
\text { ST-RSR } \\
\text { ST-FSR } \\
\text { ST-FRSR }\end{array}$ & $\begin{array}{l}6.39 \mathrm{E}-04 \\
6.40 \mathrm{E}-04 \\
6.40 \mathrm{E}-04 \\
6.39 \mathrm{E}-04 \\
6.34 \mathrm{E}-04 *\end{array}$ & $\begin{array}{l}4.51 \mathrm{E}-03 \\
4.51 \mathrm{E}-03 \\
4.51 \mathrm{E}-03 \\
4.51 \mathrm{E}-03 \\
2.75 \mathrm{E}-03 *\end{array}$ & $\begin{array}{l}1.00 \\
1.00 \\
1.00 \\
1.00 \\
0.99 *\end{array}$ & $\begin{array}{l}1.00 \\
1.00 \\
1.00 \\
1.00 \\
0.61 *\end{array}$ \\
\hline Copyright (C) 200 & ley \& Sons & & J. Fore & $587-602(2004)$ \\
\hline
\end{tabular}


Table II. Continued

\begin{tabular}{lcccc}
\hline Model & RMSE & RMSE (outliers) & Ratio & Ratio (outliers) \\
\hline ST-GARCH & $6.58 \mathrm{E}-04$ & $3.04 \mathrm{E}-03$ & 1.03 & 0.67 \\
ST-EGARCH & $6.67 \mathrm{E}-04$ & $4.32 \mathrm{E}-03$ & 1.04 & 0.95
\end{tabular}

Part 4: Switzerland

Exchange rate futures contract

$\begin{array}{lllll}\text { Basic model } & 8.35 \mathrm{E}-04 & 4.83 \mathrm{E}-03 & \ldots & \ldots \\ \text { SR } & 8.36 \mathrm{E}-04 & 4.83 \mathrm{E}-03 & 1.00 & 1.00 \\ \text { RSR } & 8.36 \mathrm{E}-04 & 4.83 \mathrm{E}-03 & 1.00 & 1.00 \\ \text { FSR } & 8.35 \mathrm{E}-04 & 4.84 \mathrm{E}-03 & 1.00 & 1.00 \\ \text { FRSR } & 8.35 \mathrm{E}-04 & 4.83 \mathrm{E}-03 & 1.00 & 1.00 \\ \text { GARCH } & 8.35 \mathrm{E}-04 & 4.83 \mathrm{E}-03 & 1.00 & 1.00 \\ \text { EGARCH } & 8.35 \mathrm{E}-04 & 4.83 \mathrm{E}-03 & 1.00 & 1.00 \\ \text { ST-Basic model } & 8.36 \mathrm{E}-04 & 4.84 \mathrm{E}-03 & 1.00 & 1.00 \\ \text { ST-SR } & 8.36 \mathrm{E}-04 & 4.84 \mathrm{E}-03 & 1.00 & 1.00 \\ \text { ST-RSR } & 8.37 \mathrm{E}-04 & 4.84 \mathrm{E}-03 & 1.00 & 1.00 \\ \text { ST-FSR } & 8.36 \mathrm{E}-04 & 4.85 \mathrm{E}-03 & 1.00 & 0.54^{*} \\ \text { ST-FRSR } & 8.11 \mathrm{E}-04^{*} & 2.64 \mathrm{E}-03^{*} & 0.97^{*} & 0.60 \\ \text { ST-GARCH } & 8.35 \mathrm{E}-04 & 2.93 \mathrm{E}-03 & 0.99 & 0.78\end{array}$

Part 5: United Kingdom

Exchange rate futures contract

$\begin{array}{lllll}\text { Basic model } & 3.34 \mathrm{E}-06 & 2.86 \mathrm{E}-05 & \ldots & \ldots \\ \text { SR } & 3.34 \mathrm{E}-06 & 2.86 \mathrm{E}-05 & 0.99 & 1.00 \\ \text { RSR } & 3.34 \mathrm{E}-06 & 2.86 \mathrm{E}-05 & 1.00 & 1.00 \\ \text { FSR } & 3.34 \mathrm{E}-06 & 2.86 \mathrm{E}-05 & 1.00 & 1.00 \\ \text { FRSR } & 3.34 \mathrm{E}-06 & 2.86 \mathrm{E}-05 & 1.00 & 1.00 \\ \text { GARCH } & 3.34 \mathrm{E}-06 & 2.86 \mathrm{E}-05 & 0.99 & 1.00 \\ \text { EGARCH } & 3.34 \mathrm{E}-06 & 2.86 \mathrm{E}-05 & 1.00 & 1.00 \\ \text { ST-Basic model } & 3.34 \mathrm{E}-06 & 2.86 \mathrm{E}-05 & 0.99 & 1.00 \\ \text { ST-SR } & 3.34 \mathrm{E}-06 & 2.86 \mathrm{E}-05 & 0.99 & 1.00 \\ \text { ST-RSR } & 3.34 \mathrm{E}-06 & 2.86 \mathrm{E}-05 & 0.99 & 0.43^{*} \\ \text { ST-FSR } & 3.34 \mathrm{E}-06 & 2.86 \mathrm{E}-05 & 0.99 & 0.43^{*} \\ \text { ST-FRSR } & 2.56 \mathrm{E}-06^{*} & 1.23 \mathrm{E}-05^{*} & 0.76^{*} & 0.69\end{array}$

Part 6: US-Canada daily exchange rate

$\begin{array}{lllll}\text { Basic model } & 1.96 \mathrm{E}-03 & 7.06 \mathrm{E}-03 & \ldots & \ldots \\ \text { SR } & 1.96 \mathrm{E}-03 & 7.06 \mathrm{E}-03 & 1.00 & 0.99 \\ \text { RSR } & 1.96 \mathrm{E}-03 & 7.07 \mathrm{E}-03 & 1.00 & 1.00 \\ \text { FSR } & 1.96 \mathrm{E}-03 & 7.06 \mathrm{E}-03 & 1.00 & 1.00 \\ \text { FRSR } & 1.96 \mathrm{E}-03 & 7.06 \mathrm{E}-03 & 1.00 & 1.00 \\ \text { GARCH } & 1.96 \mathrm{E}-03 & 7.10 \mathrm{E}-03 & 1.00 & 1.00 \\ \text { EGARCH } & 1.96 \mathrm{E}-03 & 7.09 \mathrm{E}-03 & 1.00 & 1.00 \\ \text { ST-Basic model } & 1.96 \mathrm{E}-03 & 7.06 \mathrm{E}-03 & 1.00 & 0.99 \\ \text { ST-SR } & 1.96 \mathrm{E}-03 & 7.05 \mathrm{E}-03 & 1.00 & 1.00 \\ \text { ST-RSR } & 1.97 \mathrm{E}-03 & 7.06 \mathrm{E}-03 & 1.00 & \end{array}$

Copyright () 2004 John Wiley \& Sons, Ltd.

J. Forecast. 23, 587-602 (2004) 
Table II. Continued

\begin{tabular}{lcccc}
\hline Model & RMSE & RMSE (outliers) & Ratio & Ratio (outliers) \\
\hline ST-FSR & $1.96 \mathrm{E}-03$ & $7.06 \mathrm{E}-03$ & 1.00 & 1.00 \\
ST-FRSR & $1.96 \mathrm{E}-03$ & $7.06 \mathrm{E}-03$ & 1.00 & 1.00 \\
ST-GARCH & $1.84 \mathrm{E}-03$ & $3.26 \mathrm{E}-03$ & 0.93 & 0.46 \\
ST-EGARCH & $1.8198 \mathrm{E}-3 *$ & $2.9035 \mathrm{E}-3^{*}$ & $0.92^{*}$ & $0.41^{*}$ \\
Part 7: Daily Federal funds rate & & & \\
Basic model & $9.17 \mathrm{E}-03$ & & & $\ldots$ \\
SR & $9.18 \mathrm{E}-03$ & $4.03 \mathrm{E}-02$ & $\ldots$ & 1.00 \\
RSR & $9.18 \mathrm{E}-03$ & $4.03 \mathrm{E}-02$ & 1.00 & 1.00 \\
FSR & $9.18 \mathrm{E}-03$ & $4.03 \mathrm{E}-02$ & 1.00 & 0.99 \\
FRSR & $9.18 \mathrm{E}-03$ & $4.03 \mathrm{E}-02$ & 1.00 & 1.00 \\
GARCH & $9.18 \mathrm{E}-03$ & $3.96 \mathrm{E}-02$ & 1.00 & 0.98 \\
EGARCH & $9.18 \mathrm{E}-03$ & $4.03 \mathrm{E}-02$ & 1.00 & 1.00 \\
ST-Basic model & $9.17 \mathrm{E}-03$ & $4.03 \mathrm{E}-02$ & 1.00 & 1.00 \\
ST-SR & $9.18 \mathrm{E}-03$ & $4.01 \mathrm{E}-02$ & 1.00 & 1.00 \\
ST-RSR & $9.18 \mathrm{E}-03$ & $4.03 \mathrm{E}-02$ & 1.00 & 0.99 \\
ST-FSR & $9.18 \mathrm{E}-03$ & $4.03 \mathrm{E}-02$ & 1.00 & 1.00 \\
ST-FRSR & $9.18 \mathrm{E}-03$ & $4.04 \mathrm{E}-02$ & 1.00 & 0.69 \\
ST-GARCH & $8.76 \mathrm{E}-03$ & $2.78 \mathrm{E}-02$ & 1.00 & $0.62^{*}$ \\
ST-EGARCH & $8.66 \mathrm{E}-03 *$ & $2.53 \mathrm{E}-02^{*}$ & 0.95 & \\
\hline
\end{tabular}

* Smallest RMSE.

Notes to Parts 1-5: The RMSE is the root mean squared error. The ratio statistic is the ratio of the RMSE in the particular model to the RMSE of the basic model. The basic model is a first-order autoregression, estimated by Kalman filter. The state transition (ST) is defined as a rate of change more than 2.5 times the mean absolute rate of change. The RSR is the residual scale ratio model. The FSR is the fitted scale ratio model. The FRSR is the fitted residual scale ratio model.

Notes to Part 6: The basic model is equation (25). The state transition (ST) is defined as a rate of change more than 2.5 times the mean absolute rate of change.

Notes to Part 7: The basic model is equation (24). The state transition (ST) is defined as a rate of change more than 2.5 times the mean absolute rate of change.

In sum, the ST-FRSR model yields the best results for the highly volatile intraday data, while the ST-EGARCH performs better on the daily data. Without the state transitions, however, there is little improvement in forecast accuracy. Further, models based on constructing the scale ratio for the residual dominate models using scale ratios of the overall process.

\section{FRACTALITY, ARCH PROCESSES AND VOLATILITY DIFFUSIONS}

The favourable results for the ST-EGARCH on the daily series argue that in certain cases ARCH models can approximate fractal processes. The fractal and ARCH literatures have sometimes been antagonistic, in part because multifractal models of asset returns have incorrectly used a multiplicative cascade paradigm. While the cascade mechanism is known in models of physical turbulence, it has no analogue in economics. Once it is recognized that fractality can also be generated by other types of multiplicative models, however, a key parallel between these approaches emerges. Specifically, both conditional heteroskedasticity and localized scaling symmetries can be generated by volatility diffusions. 
In continuous time, the ARCH models converge to two-factor diffusions. In the volatility diffusion literature, multiple-factor models have generally been found to be superior to the two-factor $\mathrm{ARCH}$ diffusions, because they reproduce other properties of financial market series, such as long memory (for a review, see Chernov et al., 2003). Including more stochastic factors additively, however, does not increase the number of multiplicative interactions, and should therefore not increase the degree of fractality. Instead, the key mechanism is the multiplicative relationship between stochastic factors and Levy motions. The issue now becomes identifying the type of Levy motion that can reproduce the degree of fractality observed in real-world series.

If the motion terms are specified as Brownian (the special case of Levy motion with $\alpha=2$ ), the fractal codimension is generally lower than actually observed in financial markets. One hundred simulations of three-factor models with Brownian motion were run, and tested by multiple scaling. The mean value of the estimated codimension is only 0.027 , well below the values reported in Table I. With Brownian motion and a logarithmic specification for the stochastic factor in equation (1) $\sigma\left[\exp \left(\hat{\omega}_{10}+\omega_{13} U_{3 t}\right)\right]\left(\bar{\omega}_{11} d W_{1 t}+\bar{\omega}_{13} d W_{3 t}\right)$ - the mean value of $C_{1}$ rises to 0.035 . Exponentiation leads to explosive increases at irregular intervals. A further possibility is to substitute generalized Levy motion, which encompasses heavier-tailed distributions. Simulation of stochastic volatility models with generalized Levy motion have been found to be in close agreement with the properties of empirically observed series (Barndorff-Nielsen and Shephard, 2001, 2002). A more parsimonious approach is to retain Brownian motion as the fundamental unit, but model extreme events as Poisson jumping processes. This uses two special cases of Levy motion rather than a generalized case (Duffie et al., 2000).

To evaluate these hypotheses, further experiments were run. Three-factor diffusions were simulated in discrete time using Brownian motion with Poisson jumps, and Student- $t$ motion with varying degrees of freedom. Due to space constraints, only a brief summary of the results is provided. The Poisson jumping models yielded results very similar to the logarithmic models, with $C_{1}$ averaging 0.034. For large numbers of degrees of freedom, Student $t$ motion converges to Gaussian motion, and yields comparable results. For 30 degrees of freedom, the codimension is estimated at 0.04 . As the number of degrees of freedom diminish, the tails of the Student- $t$ become heavier, and the codimension increases. With 18 degrees of freedom, Student- $t$ motion yields a mean value of the codimension in the area of 0.05 . As the degrees of freedom decline, Student- $t$ motion converges towards Cauchy motion. At very low degrees of freedom -5 or below- the codimension rises to 0.09 . With actual Cauchy motion, the value of $C_{1}$ averages 0.12 . Values of $C_{1}$ in this range are never observed in economic time series. By implication, the fundamental unit of motion in financial markets probably has heavier tails than in the Gaussian distribution, but not as heavy as in the Cauchy.

Finally, multivariate diffusions that capture simultaneous equation relationships have also been found to replicate actual financial market behaviour (Johnson, 2002). Let $Y_{t k}$ be a vector of $k$ time series, $\sigma_{t k}$ be a vector of $k$ diffusion coefficients, and let $\Xi_{k}$ and $\Omega_{k}$ be matrices of structural coefficients. A simultaneous equation diffusion system can be written:

$$
\begin{aligned}
& d Y_{t k}=\Xi_{1 k} U_{2 t k} d t+\sigma_{t k} U_{3 t k} \Omega_{1 k}\left(d W_{1 t k}+d W_{3 t k}\right) \\
& d U_{2 t k}=\Xi_{2 k} d t+\Omega_{2 k} d W_{2 t k} \\
& d U_{3 t k}=\Xi_{3 k} d t+\Omega_{3 k} d W_{3 t k}
\end{aligned}
$$

If the model structure is simultaneous rather than recursive, then the reduced forms of the equations will involve multiplicative relationships among the coefficients. If the coefficients are time-varying 
at high frequencies, this introduces an additional multiplicative factor. A final set of simulation experiments were run to evaluate simultaneous equation systems. With some stochastic variation in the coefficients, the fractal codimension was found to lie in a range of 0.05 to 0.11 . The lower values of these estimates are more consistent with the observed values, implying only minor coefficient variation.

\section{CONCLUSIONS}

Volatility diffusions with various types of Levy motion-Brownian motion with Poisson jumps, Student- $t$ motion, as well as simultaneous equation systems - are all capable of reproducing the fractality observed in the real world. If the fundamental data-generating process can be represented by a stochastic volatility diffusion, then it is possible to forecast either using models of the diffusion coefficient, as in the ARCH class, or models of the localized scaling symmetry, as in the SR class. Neither approach necessarily dominates the other, but both classes can be enhanced by including state transitions. Of the fractal paradigms tested here, the optimal model for the intraday exchange rate futures contract is the ST-FRSR, which reduces the predictive error primarily by capturing extreme fluctuations more accurately. The forecast error during the outlying events is reduced by between two-fifths and three-fifths, a highly significant outcome.

\section{REFERENCES}

Andersen TG. 1994. Stochastic autoregressive volatility: a framework for volatility modeling. Mathematical Finance 4: 75-102.

Andersen TG, Bollerslev T. 1997. Heterogeneous information arrivals and return volatility dynamics: uncovering the long-run in high frequency returns. Journal of Finance 52: 975-1005.

Andersen TG, Lund J. 1997. Estimating continuous-time stochastic volatility models of the short-term interest rate. Journal of Econometrics 77: 343-377.

Andersen TG, Chung HJ, Sorensen BE. 1999. Efficient methods of moments estimation of a stochastic volatility model: a Monte Carlo study. Journal of Econometrics 91: 61-87.

Barndorff-Nielsen OE, Shephard N. 2001. Non-Gaussian Ornstein-Uhlenbeck based models and some of their uses in financial economics. Journal of the Royal Statistical Society, Series B 63(2): 167-241.

Barndorff-Nielsen OE, Shephard N. 2002. Econometric analysis of realized volatility and its use in estimating stochastic volatility models. Journal of the Royal Statistical Society, Series B 64(2): 253-280.

Bates DS. 1996. Jumps and stochastic volatility: exchange rate processes implicit in DM options. Review of Financial Studies 9: 69-107.

Beran J. 1992. Statistical methods for data with long-range dependence. Statistical Science 7: 404-427.

Bollerslev T. 1986. Generalized autoregressive conditional heteroskedasticity. Journal of Econometrics 31: 307-327.

Bollerslev T, Mikkelsen HO. 1996. Modeling and pricing long memory in stock market volatility. Journal of Econometrics 73: 151-184.

Brock W, Sayers C. 1988. Is the business cycle characterized by deterministic chaos? Journal of Monetary Economics 22: 71-90.

Calvet L, Fisher A. 2002. Multifractality in asset returns: theory and evidence. Review of Economics and Statistics 84: 381-406.

Chernov M, Gallant AR, Ghysels E, Tauchen G. 2003. Alternative models for stock price dynamics. Journal of Econometrics 116: 225-257.

Copyright (@) 2004 John Wiley \& Sons, Ltd.

J. Forecast. 23, 587-602 (2004) 
Duffie D, Pan J, Singleton K. 2000. Transform analysis and option pricing for affine jump-diffusions. Econometrica 68: 1343-1377.

Fouque JP, Papanicolaou G, Sircar KR. 2000. Mean-reverting stochastic volatility. Journal of Theoretical and Applied Finance 3: 101-142.

Gallant AR, Hsu CT, Tauchen G. 1999. Using daily range data to calibrate volatility diffusions and extract the forward integrated variance. Review of Economics and Statistics 81: 617-631.

Gray SF. 1996. Modeling the conditional distribution of interest rates as a regime-switching process. Journal of Financial Economics 42: 27-62.

Hamilton JD. 1989. A new approach to the economic analysis of nonstationary time series subject to changes in regime. Econometrica 57: 357-384.

Hamilton JD. 1994. Specification testing in Markov-switching time series models. Journal of Econometrics 70: 127-157.

Hsieh D. 1991. Chaos and nonlinear dynamics: application to financial markets. Journal of Finance 46: $1839-1877$.

Hsieh D. 1993. Implications of nonlinear dynamics for financial risk management. Journal of Financial and Quantitative Analysis 28: 41-64.

Huisman R, Koedijk KG, Kool CML, Palm F. 2001. Tail index estimates in small samples. Journal of Business and Economic Statistics 19: 208-216.

Hurst HE. 1951. The long-term storage capacity of reservoirs. Transactions of the American Society of Civil Engineers 116: 770-808.

Johnson TC. 2002. Volatility, momentum and time-varying skewness in foreign exchange returns. Journal of Business and Economic Statistics 20: 390-411.

Kalman RE. 1960. A new approach to linear filtering and prediction problems. Transactions of the American Society of Mechanical Engineers, Journal of Basic Engineering 83D: 35-45.

Lavallee D, Schertzer D, Lovejoy S. 1991. On the determination of the codimension function. In Nonlinear Variability and Geophysics: Scaling and Fractals, Schertzer D, Lovejoy S (eds). Kluwer: Dordrecht; 99110.

Lavallee D, Lovejoy S, Schertzer D, Schmitt F. 1992. On the determination of universal multifractal parameters in turbulence. In Dynamics of Fluids and Plasmas, Moffatt HK et al. (eds). Kluwer: Amsterdam; 463-478.

Mandelbrot B. 1997. Fractals and Scaling in Finance. Springer: New York.

Mantegna RN, Stanley HE. 1995. Scaling behavior in the dynamics of an economic index. Nature 376: 46-49.

Mantegna RN, Stanley HE. 1996. Turbulence and financial markets. Nature 383: 587-588.

Mantegna RN, Stanley HE. 1997. Stock market dynamics and turbulence: parallel analysis of fluctuations phenomena. Physica A 239: 255-266.

Mantegna RN, Stanley HE. 1998. Physics investigation of financial markets. In Proceedings of the International School of Physics, Mallamace F, Stanley F (eds). IOS Press: Amsterdam; 473-489.

Mantegna RN, Stanley HE. 1999. An Introduction to Econophysics: Correlations and Complexity in Finance. Cambridge University Press: Cambridge.

Medio A. 1992. Chaotic Dynamics Theory and Applications to Economics. Cambridge University Press: Cambridge.

Nelson DB. 1991. Conditional heteroskedasticity in asset returns: a new approach. Econometrica 52: 347-370.

Richards GR. 2002. Fractality in a macroeconomic model: nonlinear oscillation around an underlying equilibrium. Fractals 10: 235-251.

Schertzer D, Lovejoy S. 1991. Scaling and nonlinear variability in geodynamics: multiple singularities observables and universality classes. In Nonlinear Variability and Geophysics: Scaling and Fractals, Schertzer D, Lovejoy S (eds). Kluwer: Dordrecht; 41-82.

Schertzer D, Lovejoy S, Schmitt F, Chigirinskaya Y, Marsan D. 1997. Multifractal cascade dynamics and turbulent intermittency. Fractals 5: 427-471.

Schmitt F, Lavallee D, Schertzer D, Lovejoy S. 1992. Empirical determination of universal multifractal exponents in turbulent velocity fields. Physical Review Letters 68: 305-308.

Schmitt F, Schertzer D, Lovejoy S, Brunet Y. 1993. Estimation of universal multifractal indices for atmospheric turbulent velocity fields. Fractals 1: 568-575.

Schmitt F, Schertzer D, Lovejoy S. 1999. Multifractal analysis of foreign exchange data. Applied Stochastic Models and Data Analysis 15: 29-53.

Terasvirta T. 1994. Specification estimation and evaluation of smooth-transition autoregressive models. Journal of the American Statistical Association 89: 208-218. 
Author's biography:

Gordon R. Richards is a statistician with Sprint Telecommunications. He has also worked with Intel. His research interests include econometric models as well as time series analysis.

Author's address:

Gordon R. Richards, Sprint Telecommunications, 6180 Sprint Parkway, Overland Park, KS 66251, USA. 
Reproduced with permission of the copyright owner. Further reproduction prohibited without permission. 